\title{
INTERNET-ASSISTED LABORATORY EXPERIMENTS FOR DISTANCE LEARNING SYSTEMS.
}

\author{
L.G. Guerrero, J. Carrillo \& J.M. Ramírez \\ Departamento de Ingeniería Electrónica \\ E. Palou, A. López-Malo \& J. Welti-Chanes \\ Departamento de Ingeniería Química y Alimentos \\ Universidad de las Américas, Puebla \\ Cholula, Puebla 72820, MEXICO \\ (222) 229-2658, 229-2258 fax \\ lgojeda@mail.udlap.mx
}

\author{
R.P. Singh \& K. Athmaram \\ Biological and Agricultural Engineering \\ University of California, Davis \\ 2042 Bainer Hall \\ Davis, CA 95616 \\ USA \\ (530) 752-0811, 752-5293 fax \\ rpsingh@ucdavis.edu
}

\begin{abstract}
Universities are increasingly using the Internet to improve undergraduate teaching, since it provides access to sources not conveniently obtainable through other means, allows for the creation of unusually rich course materials, it is an exceptionally fine tool for creating densely woven, engaging, and highly demanding new course materials, and it can reinforce the conception of students as active agents in the process of learning while enhancing discussion groups unbounded by time or place (Singh, 1996; 2002). The objectives were:

i) to create a set of instructional laboratory exercises, mainly in the areas of food and bioprocess engineering that contain remotely conducted experiments assisted by the Internet,

ii) to develop a complete set of instructions including software on how remotely conducted laboratories may be set up by an instructor, and iii) to evaluate the role of remotely conducted experiments in the effectiveness of teaching food and bioprocess engineering in undergraduate education.
\end{abstract}

\section{Introduction}

Internet-assisted laboratory experiments were created to complement undergraduate engineering courses and offered for worldwide use on the Web. The experiments are:

a) Dynamic response of sensors, convective heat transfer coefficient of air,

b) Thermal conductivity of foods and biomaterials,

c) Image processing to determine shape characteristics

of food and biomaterials,

d) Heat and mass balance across an air dryer,

e) Monitoring of electrical parameters of either a DC or an $\mathrm{AC}$ motor.

Each of these experiments has different components of complexity, from static measurement to dynamic movement of a selected piece of hardware. Thus, the experiments provide useful information to instructors who may want to develop new Internet mediated exercises. A complete set of instructions including software on how remotely conducted laboratories may be set up, are available to motivate other instructors to create additional Internet-assisted laboratory experiments.

The six experiments developed in this project have been extensively used in teaching food engineering courses at the University of California, Davis and Universidad de las Américas, Puebla. Students in different lecture and laboratory classes have been assigned these experiments. Students had access to these remote-controlled laboratory exercises, and were able to conduct "hands-on" experiments at a computer. "Handson" implies that a student carries out various tasks, while the manipulated (live mode) apparatus, may be located in another country. The laboratory exercises are now Internet-available (for a fixed-time duration) to interested students and teachers worldwide.

\section{Project Efectiveness}

We evaluated project effectiveness based on selected questions at the end of each experiment to assess student understanding of the tasks just completed. Furthermore, at the end of a course feedback was obtained through written evaluations as well as from student and instructor reflections. Results demonstrate that this innovative approach of using the Internet has considerable merit in enhancing learning (Courtois and Singh, 2002; Palou et al., 2003). The positive feedback received from students indicates that these exercises are useful in laboratory classes to develop a self-paced understanding of a concept. In lecture-only classes, students noted that this experience enhanced their learning of concepts that were difficult to understand from reading textbooks. The Internet mediated laboratories have been most advantageous in engaging students in an interactive Internet activity prior to conducting a more comprehensive laboratory experiment. With the pre- 
exposure to the topic at hand, students are better prepared to discuss issues relevant to a given exercise.

\section{Hardware and Sensors}

As an example the experiment Dynamic Response of Sensors is briefly described: Sensors are used to sense the change in the property of the environment in which they are employed and thus control the environment according to the need. The time constants of the sensors like resistance temperature detectors (RTD), thermocouple, and thermistor reveal valuable information about their operation, behavior and capability for use in different applications. A property of the environment, for example temperature is sensed by measuring a change in the voltage as in a thermocouple or by the change in the resistance as in the case of thermistor and RTD. A time constant of a temperature sensor such as a thermocouple is a measure of how rapidly the sensor responds to the change in the environmental temperature. The principle of operation of a sensor depends on the different types of sensor designs. In case of a thermocouple, the thermoelectric voltage generated when the junction of two dissimilar metals is heated, is interpreted to give the temperature of the junction. A resistance temperature detector (RTD) operates on the principle of the change in electrical resistance in wire as a function of temperature. A thermistor is similar to an RTD operating on changes in electrical resistance with changes in temperature. Resistance values are correlated to give the temperature. Time constants are calculated on the basis of the sensors reaching $63.2 \%$ of the final value to a step change in the temperature.

Sensors used in this experiment are a thermocouple, an RTD and a thermistor. A heater is used to heat the air, and a fan is used to blow the heated air at equilibrium temperature past the sensors, past the sensors. Reference temperature of the heater is measured by a thermocouple. And a gate is used to give a step change in the temperature by forcing the heated air into the inner pipe where the sensors are kept. The parameters for the experiment include the gate control, and a heater unit. For the gate control, a motor is used which when excited produces a sliding motion used to open the gate. When the motor is not excited, the gate closes the entrance of air to the inner pipe. To measure the reference temperature of the heater unit, a thermocouple is used close to a steel mesh, in line with the sensor positions, in the inner pipe. Since there is a gradient in the temperature of the airflow, the alignment of the reference thermocouple and the three sensors inside the pipe must be properly taken care of to prevent the ambiguity in the measurements. The gate has a digital control (On - when motor is excited and Off when motor is not excited). While the heater has an analog control (varied from $0 \%$ to $100 \%=400 \mathrm{~W}$ )

\section{Sensor Dynamics Experiment at UC Davis}

Hardware setup consists of two pipes of different diameters such that one slides through the other (Figure 1). The inner pipe, on one of its end, has the motor control for the gate, which is fixed to the end. Holes for the sensors are drilled across a point in the inner pipe in a way that alignment does not hinder the airflow. At one end of the outer pipe a fan unit is kept and two bulbs, each rated at $200 \mathrm{~W}$, are installed for analog control of the heater unit. A steel mesh is kept next to the bulbs to facilitate the heat distribution and prevent radiation. A hole for a reference thermocouple is also drilled (Figure 2).

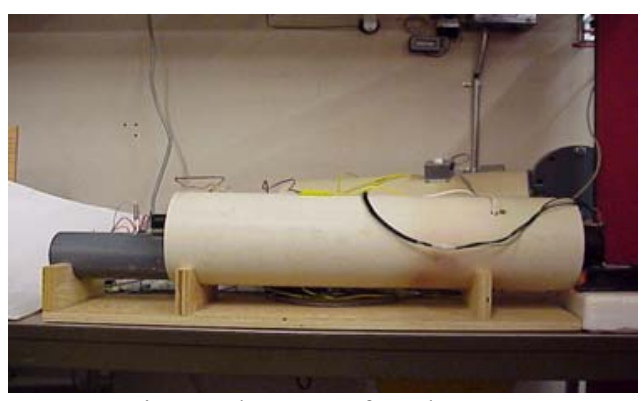

Figure 1 Experimental Setup for the Sensor Dynamics Experiment.

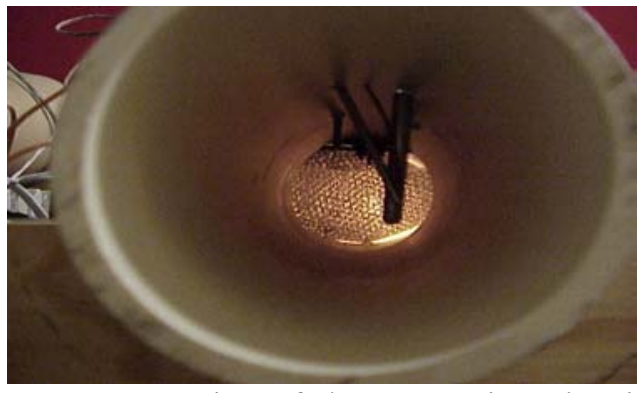

Figure 2 Cross Section of the Inner Pipe Showing the Sensors, Gauge and Bulb.

The procedure to remotely conduct the experiment Dynamic Response of Sensors is as follows: The apache web server is started and labserverd, the server program for the sensor dynamics experiment, is executed so that the server is ready to accept host connections. Apache server broadcasts the default static homepage on the server's address (in this particular case, http://foodlab.engr.ucdavis.edu) as shown in Figure 3. The server greets the host with its resources. When the host clicks the link for the sensor dynamics experiment, the labserverd gets started. First it asks for the host's username and password. If those are not correct, the host is a passive observer and is allowed to view the experimental setup. Upon proper authentication of the host, a live setup of the experiment with a link taking to controls is displayed (Figure 4). On clicking the link and 
authenticating again, the host is taken to the controls, where the heater values (from the scale of 0 to 100) as well as the gate condition (either open or closed) can be controlled. Meantime the user is shown the live image shot by the web cam and the values of the sensors like temperature of the ambient thermocouple and sensor thermocouple, RTD temperature and thermistor temperature are displayed continuously with respect to the acquisition rate.

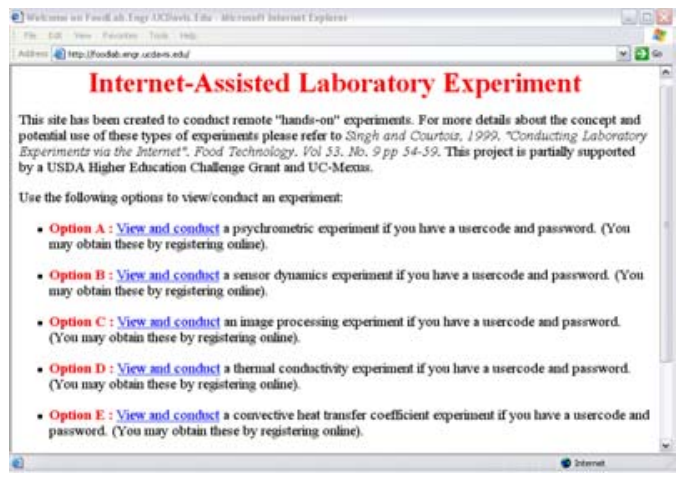

Figure 3 Home Page.

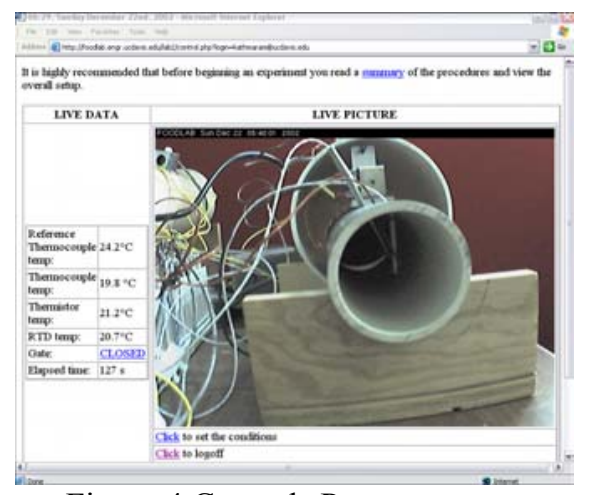

Figure 4 Controls Page.

The server tracks the user's time and once it gets expired or equals the time allotted for the session, the host is logged out (Figure 5), and a feedback form to be answered by the user is displayed.

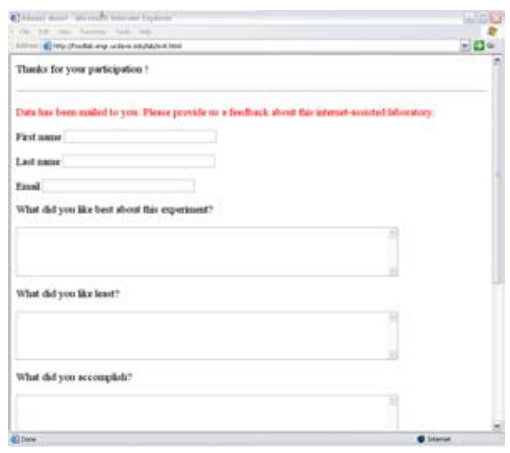

Figure 5 Session End with a Feedback Form.
The data from every experiment are sent to the user's mailbox, copied and saved in a Microsoft Excel ${ }^{\mathrm{TM}}$ format with the extension.$x l s$. The user opens the file through the Excel program and delimits accordingly to obtain the file in a specified format. The data could then be analyzed.

The columns of the data collected in a particular experiment are as follows: time, reference temperature, thermistor, RTD, thermocouple, heater value and the status of the gate control. The time after the gate opens is taken as the reference time, i.e., time is taken as $0 \mathrm{~s}$ when the gate opens. The reference temperature is taken as the ambient temperature, $\mathrm{Ta}$, and the initial temperature of the sensors, $\mathrm{Ti}$, when the gate opens. $\mathrm{T}$ is the temperature sensed by the sensors with time. Natural logarithm of (Ta $-\mathrm{T}) /(\mathrm{Ta}-\mathrm{Ti})$ is calculated and plotted versus time. A trend line is fitted for the data plotted and the equation gives the slope of the line. The inverse of the slope gives the time constants of the sensors as presented in Table 1. The average time constant of the five replicates for thermocouple is $18.97 \mathrm{~s}$ with a standard deviation of 0.76 s. As expected, thermocouple responds fastest to a step change in the environmental temperature, whereas RTD is the slowest of the tested sensors.

\begin{tabular}{|c|c|c|c|}
\hline & \multicolumn{3}{|c|}{ Time Constant (s) } \\
\hline Trial & Thermocouple & RTD & Thermistor \\
\hline 1 & 19.92 & 88.5 & 46.95 \\
\hline 2 & 17.92 & 87.72 & 38.17 \\
\hline 3 & 19.38 & 86.21 & 35.71 \\
\hline 4 & 19.01 & 84.03 & 34.13 \\
\hline 5 & 18.62 & 83.33 & 42.74 \\
\hline $\begin{array}{c}\text { Average } \\
\text { Standard }\end{array}$ & $\mathbf{1 8 . 9 7}$ & $\mathbf{8 5 . 9 6}$ & $\mathbf{3 9 . 5 4}$ \\
\hline
\end{tabular}

Table 1. Time Constants of Sensors -Sensor Dynamics Results.

\section{Heat and Mass Balance Across an Air Dryer Experiment at Universidad de las Americas, Puebla}

The web page of the experiments developed in Universidad de las Américas, Puebla is available in English language and in Spanish. In this section are shown the results obtained with the Heat and Mass Balance Across an Air Dryer Experiment, figure 6 shows the Home page in spanish. 


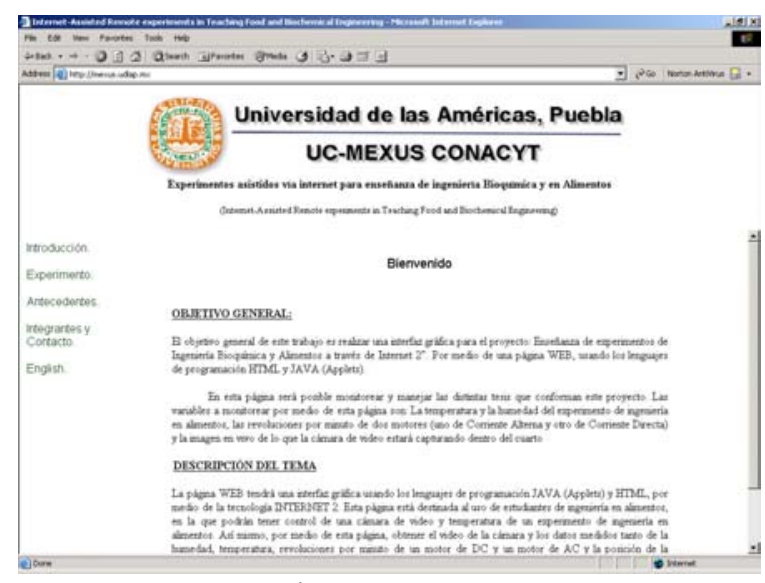

Figure 6 Home Page.

The user can choose to realize any of the experiments shown in figures 7 .

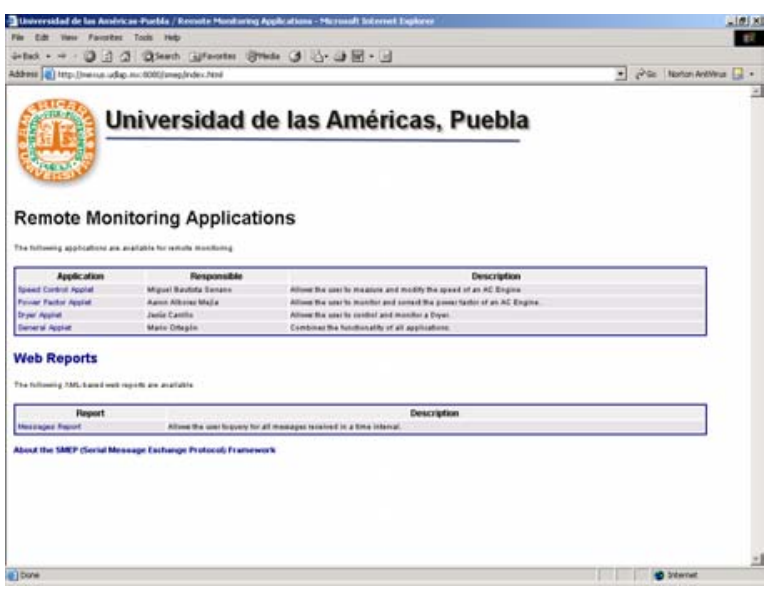

Figure $7 \mathrm{Web}$ page of the experiments developed in the Universidad de las Americas, Puebla..

The user can also monitor the actual status of the system by means of a remote camera system live view shown in figure 8 .

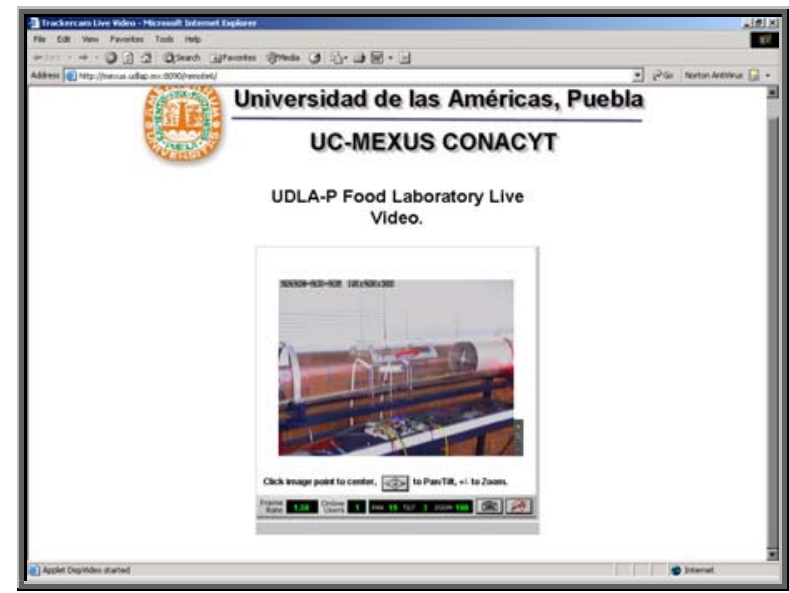

Figure 8 Experiment live view.
The user can set many parameters of the system such as:

a) Air flow speed, any of: $25 \%, 50 \%, 75 \%$ or $100 \%$.

b) Bulb temperature.

Figure 9 shows (left upper side rectangle) when Air flow speed is set to $100 \%$ and Bulb temperature is set to 50 degrees Celsius, after these values are set user must push start button in order to run the experiment.

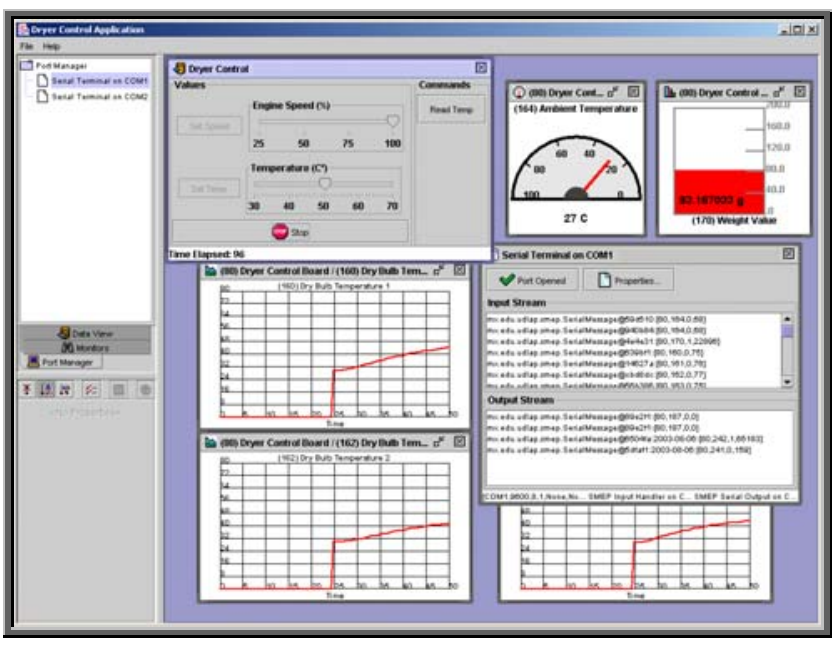

Figure 9 Experiment run an set up web page.

Figure 9 shows also six monitors:

a) Upper right corner, in red color, shows the tracking of the food weight.

b) ) At the left of the food weight monitor is shown the ambient temperature monitor.

c) Down from the middle are shown in full two graphics with a red line, these are the dry bulb temperature monitors.

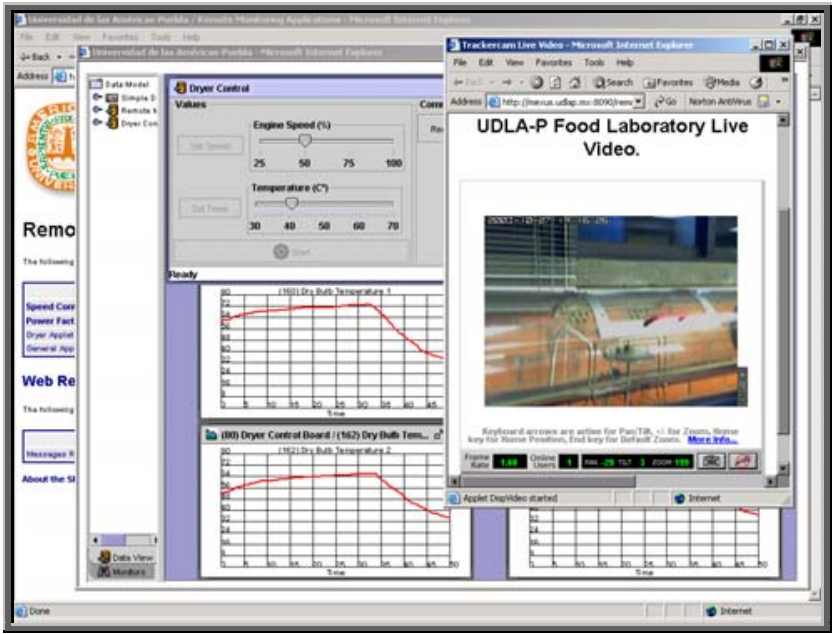

Figure 10 Experiment run with the live video with zoom and dry bulb temperatura changing. 


\section{Conclusions}

At selected international conferences, remote control of laboratory experiments across continents has been demonstrated. Demonstrations have provided new opportunities to conduct joint experiments with some foreign institutions. Furthermore, students from Argentina have conducted Internet-mediated experiments. The opportunities for student interaction across borders and different continents offer new paradigms to enhance learning and collaboration.

While we know that our experiments change the teaching and learning experience, we do not have hard, consistent evidence documenting that they enhance academic achievement and learning outcomes in order to be sure that we have transformed the laboratory experiments, instructional activities of the faculty and/or the learning experiences of most students. Therefore our future plans, are to develop, for every experiment, new forms of assessment that focus on establishing what students have learned, the knowledge and skills they have achieved, their potential for further independent learning (Angelo and Cross, 1993; Brakke and Brown, 2002; Speck, 2002) as well as the usability (Mehlenbacher, 2002) of the remote experiments while engaging students from UDLA with those from UC Davis in bi-national teams to conduct experiments on a remote basis and prepare joint laboratory reports (Nicolay, 2002). This will allow students to collaborate on the Internet by collecting and analyzing real-time data. Depending on the outcomes assessment of our attempt, we will seek similar joint opportunities with other institutions in Mexico, United States and abroad.

\section{References}

[1] Angelo TA, Cross KP. 1993. Classroom Assessment Techniques: A Handbook for College Teachers (2nd Ed.) Jossey-Bass, San Francisco.

[2] Brakke DF, Brown DT. 2002. Assessment to Improve Student Learning. New Directions for Higher Education, 119: 119-122.

[3] Courtois F, Singh RP. 2002. A Low-Cost, Versatile Laboratory Experiment in Food Engineering Using the Internet. In Engineering and Food for the 21st Century, J Welti-Chanes, GV Barbosa-Canovas, JM Aguilera (Ed.) CRC Press, Boca Raton, Florida, pp. 1035-1041.

[4] Mehlenbacher B. 2002. Assessing the Usability of On-Line instructional Materials. New Directions for Teaching and Learning, 91: 91-98.
[5] Nicolay JA. 2002. Group Assessment in the On-Line Learning Environment. New Directions for Teaching and Learning, 91: 43-52.

[6] Palou E, Welti-Chanes J, Ramírez JMGuerrero LG, López-Malo A, Carillo J, Singh RP, Athmaram K. 2003. Internet-Assisted Remote Experiments in Teaching Food and Bioprocess Engineering. 2003 ASEE Annual Conference, Nasville, TN.

[7] Singh RP. 1996. Teaching Food Science and Technology on the World Wide Web. Food Technology, 50(3): 94-99.

[8] Singh RP. 2002. Role of the Internet in Food Engineering Teaching. In Engineering and Food for the 21 st Century, J Welti-Chanes, GV Barbosa-Canovas, JM Aguilera (Ed.) CRC Press, Boca Raton, Florida, pp. 1013-1021.

[9] Speck BW. 2002. Learning-Teaching-Assessment Paradigms and the On-Line Classroom. New Directions for Teaching and Learning, 91: 5-18 